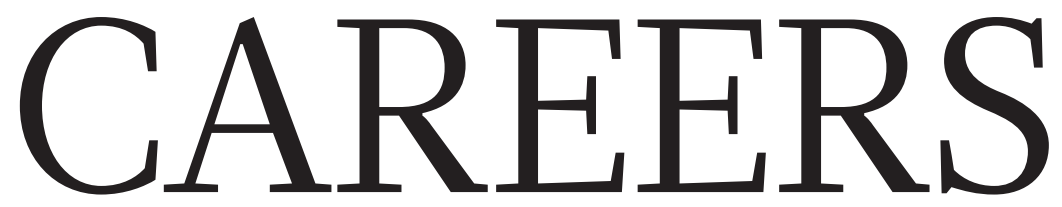

TURNING POINT Materials scientist hopes tenure will facilitate new research $\mathbf{p . 4 5 9}$
FUNDING US National Academies suspends popular policy fellowship $\mathbf{p . 4 5 9}$
NATUREJOBS For the latest career

listings and advice www.naturejobs.com

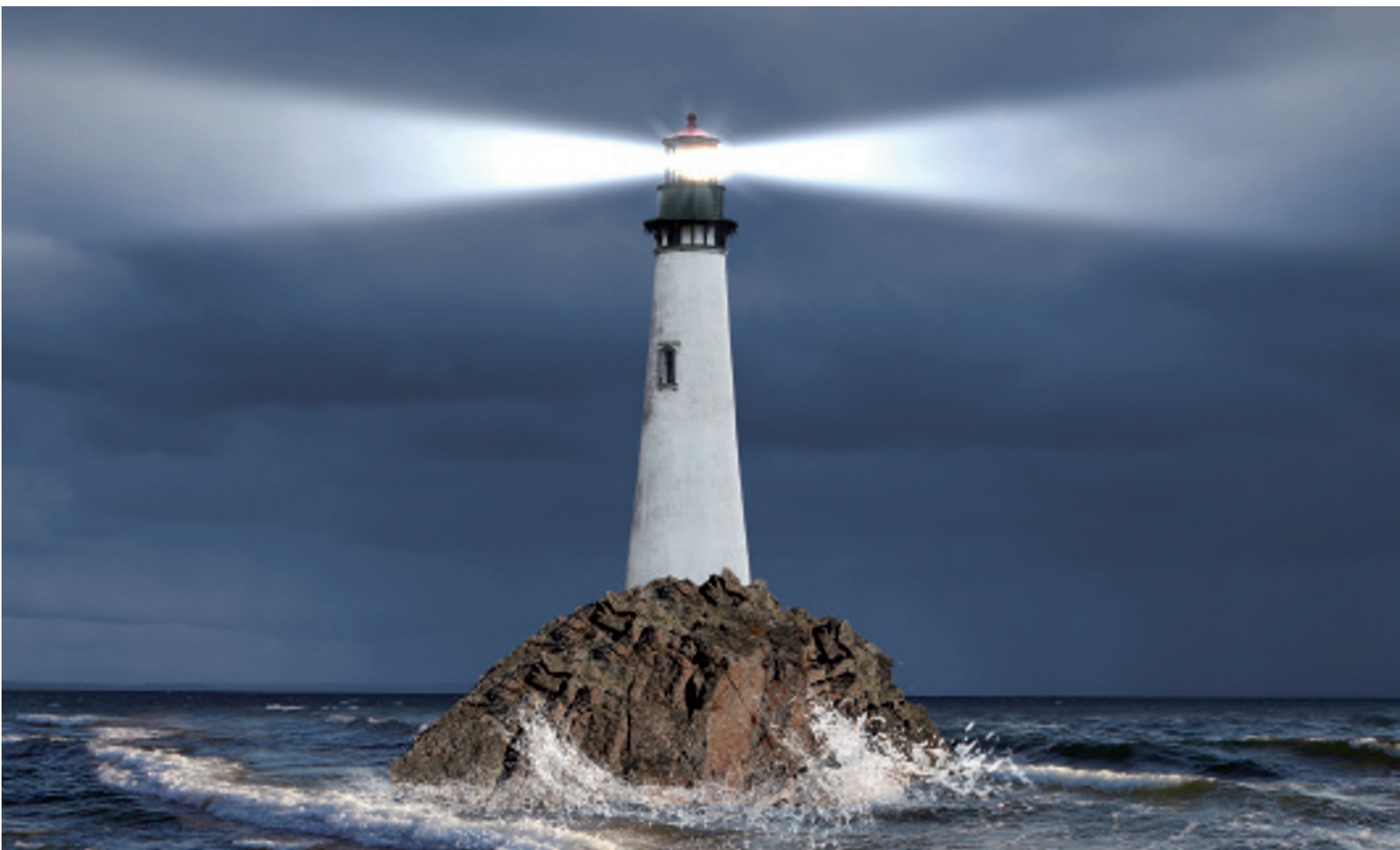

COLUMN

\title{
Guiding lights
}

\section{The three Nordic winners of this year's Nature mentoring awards respond exceptionally to scientific and personal challenges, says Philip Campbell.}

A s a judge of the 2012 Nature Awards for Mentoring in Science, this year featuring the Nordic countries, I noticed that the anecdotes from nominators of one of the short-listed candidates seemed rather cooler in their enthusiasm than others. "Ah," said my fellow judges, who hailed from around the region, "they're from the north."

Nominators from the Nordic nations' more northern reaches may have tended to be more muted in their praise, but trainees and colleagues sent ample compliments for all this year's short-listed candidates - especially the winners. All three have mentored students and postdocs who have subsequently flourished. But trainees' accomplishments, although important, are just one measure of success. The judges place as much emphasis, if not more, on the human qualities of mentors - their willingness to enable trainees to pursue their own interests, generosity with their time and their ability to serve as a role model as a scientist and lab leader.

This year's judges were drawn from Sweden, Norway, Finland and Denmark, as were the 20 entries. As it happens, all the winners hail from Sweden. The $€ 10,000$ (US $\$ 12,900$ ) mid-career award for achievements in mentoring is split between Jens Nielsen, a systems biologist at Chalmers University of Technology in Gothenburg, and Anders Hagfeldt, dean of chemistry at Uppsala University. The winner of the $€ 10,000$ lifetime-achievement award is microbiologist and molecular biologist Staffan Normark, now secretary of the Royal Swedish Academy of Sciences in Stockholm, after posts at Umeå University in Sweden, Washington University in St. Louis and the Karolinska Institute in Stockholm.

\section{WISE COUNSEL}

One nominator lauded Nielsen's knack for instantly grasping the challenges of a project and assisting trainees in tackling them. "Jens has the talent to be on top of projects within a few minutes, and thereby is able to contribute 

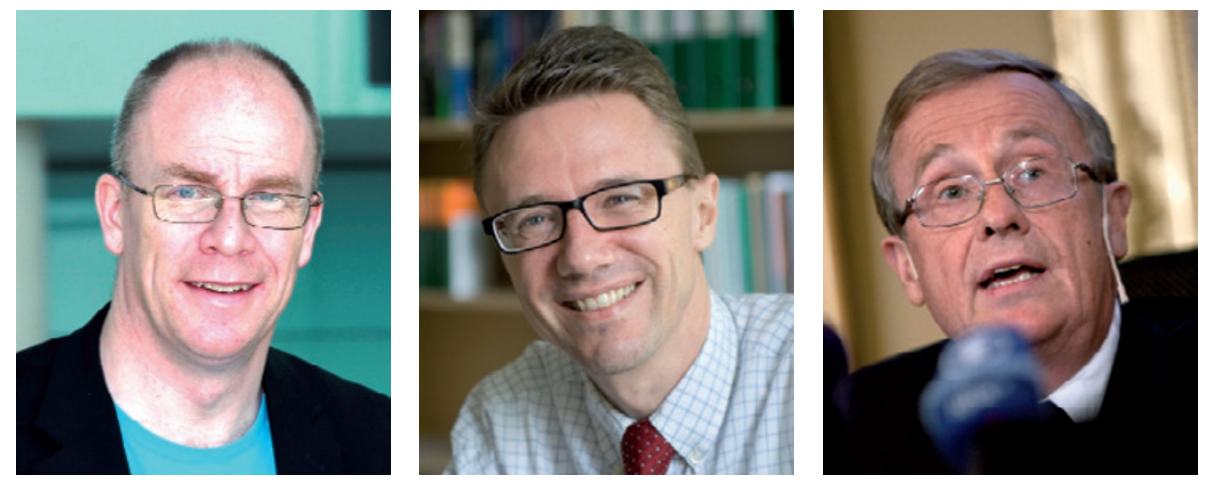

Anders Hagfeldt (left), Jens Nielsen (centre) and Staffan Normark help their trainees to fulfil their potential.

> rapidly with input on any ongoing projects," says Jochen Förster, chief technology officer at the Novo Nordisk Foundation Center for Biosustainability at the Technical University of Denmark in Hørsholm. "This allows him to run large research groups and to continuously attract a high number of national and international PhD students and postdocs."

Hagfeldt, too, is an astute manager: "His delegation of workload ensures that young researchers develop key skills," said one nominator. "The most important attribute of Anders Hagfeldt as a mentor is the trust he places in his students and researchers," said another.

Both have found ways to make time, despite hectic schedules. Nielsen "always found time to hear out colleagues", noted one nominator. "His extremely large network meant that if a project was stuck he would always know somebody could help." Another noted that Hagfeldt held weekly coffee meetings to discuss lab issues and weekly lunch meetings for scientific themes.

Some of the simplest attributes were among the most valued. Hagfeldt is a great listener, said trainees. "He is very humble and just lets the other person talk and just with some small questions guides the person in the right direction," said Tomas Edvinsson, a chemist at Uppsala University. "He encourages cooperation internally and with other groups nationally and internationally in an open spirit." Hagfeldt says that he tries to "be supportive in the daily harsh work of research and to give confidence that sooner or later the work will pay off".

Some of Nielsen's key mentoring moments have come when his protégés faced crises. "The most frequent cause of 'depressions' and loss of motivation comes from researchers suddenly becoming overwhelmed by the task and sudden feeling of lack of confidence," he says. "I assist them with breaking down the tasks into smaller units and encourage them daily to carry out small tasks so they eventually feel they had made progress and faith in their own abilities."

\section{POTENTIAL FOR GREATNESS}

Like most great mentors, Normark demonstrates an ability to tease out the best in his co-workers. Scott Hultgren, a former trainee, recalled how he had joined Normark's lab in Umeå with potential, but few accomplishments or publications. "He saw something in me that he was able to foster, nurture, inspire and motivate," said Hultgren, now a microbiologist at the Washington University School of Medicine in St. Louis, and a member of the US National Academy of Sciences, with more than 200 publications. "There are countless examples of this 'before-Staffan' and 'after-Staffan' paradigm where he has recruited a young scientist, typically with very few metrics that would be predictive of future achievements, and nucleated their career paths in successful trajectories."

Normark says that his own mentor was a big influence on his mentoring style. "He never put two postdocs on the same project or even the same pathogen, to avoid internal competition," he recalls, "and constantly started new innovative projects whenever a postdoc left the lab together with his or her project."

Another nominator praised Normark's tendency to encourage trainees to pursue their interests even when that came at a cost to his own research programme. That generosity came along with a healthy dose of investigative freedom. "He gave us the impression that he was more interested in novelty than incremental findings," said "Weall wanted the nominator. "He to be like him and he inspired us to become better scientists." always emphasized creativity over sheer data production."

Normark also led by example, offering a steady presence in the face of frustrations and setbacks. "We all wanted to be like him and he inspired us to become better scientists," said a nominator. "His outlook was always positive and calming when times were rough. I never saw Staffan frustrated by a bad result or slow productivity." That also meant shielding trainees from the stresses of ancillary duties. "He never shared any frustrations with rejections or university politics with his students," said another nominator. Principal investigators "don't realize how much the expression of their frustrations impact the life and career decisions of their students and postdocs".

Philip Campbell is editor-in-chief of Nature and the founder of the Nature Awards for Scientific Mentoring. 